Address for Correspondence: Prof. Lawrence Grouse, MD, PhD, Department of Neurology,

University of Washington School of Medicine, Rm RR650, Seattle,

Washington 98195-6465, USA

Email: Igrouse@uw.edu

\begin{tabular}{|l|}
\hline Access this article online \\
\hline $\begin{array}{l}\text { Website: } \\
\text { www.intern-med.com }\end{array}$ \\
\hline DOI: \\
10.1515/jtim-2015-0020 \\
\hline Quick Response Code: \\
\hline \\
\\
\\
口) \\
\hline \\
\hline
\end{tabular}

\title{
Translational genetic research of complex diseases
}

\author{
Lawrence Grouse ${ }^{1,2}$ \\ 'Executive Director, International COPD Coalition; \\ ${ }^{2}$ University of Washington School of Medicine, Gig Harbor, Washington, USA
}

\section{INTRODUCTION}

Because of the advances in genome science, translational research on the genetics of chronic obstructive pulmonary disease (COPD) could provide substantial benefit for COPD patients and improve the prospects for COPD prevention. ${ }^{[1]}$ In addition, translational research on the genetics of other complex diseases such as neurodevelopmental disorders offers the possibility of a better understanding of their causes and treatment. ${ }^{[2]}$ This review addresses the practical issue of how the increased global translational research effort on complex diseases should proceed and the likely barriers to this effort.

Complex disease is defined as a phenotype that is not caused by a single gene mutation but by many individual gene events, and with a significant contribution from environmental factors. Classical approaches to complex disease have identified patients with similar phenotypes and have attempted to identify a common causative mutation. In most cases the heritability of complex disease is unresolved using this strategy. COPD, for example, can be caused by abnormal alleles of alpha- 1 antitrypsin, and other genetic abnormalities exist among COPD patients, but no common causative mutation has been found in familial COPD cases. COPD's association with tobacco use and other forms of toxic inhalation is clear in many patients, and epigenetic factors may play a role in its development. ${ }^{\left[{ }^{[3]}\right.}$

The genetic heterogeneity exemplified by COPD requires a shift in the approach to studying the genetics of the disease. By sequencing patients' exomes and comparing them with controls, a variety of genetic causes of their disease can often be identified. The exome is the portion of the genome that codes information for protein synthesis. Investigators can leverage new sequencing technology to genetically classify subtypes of COPD. This involves candidate causal gene discovery and determination of pathogenicity, comprehensive clinical phenotyping, and resolution of genetic background effects. The initial application of this genotype first examination approach to diagnosis is particularly applicable for complex diseases in which the molecular causes are not currently understood. This includes a substantial portion of patients' illnesses.

In the US, the COPD Foundation is working with the COPDGENE Initiative (www. copdgene.org) in their studies analyzing genome-wide associations with COPD. Dr. Ed Silverman, who supervises many of the initiative's activities, believes that there is increasing interest in research on the genomic pathology of COPD. The International COPD Coalition (ICC; www.internationalcopd.org) advocates that researchers worldwide be encouraged to conduct genetic research in COPD and that funding for these workers should be prioritized.

Patients with COPD need the best care that physicians can give them, but with our limited understanding of the causes of the disease subtypes that make up COPD, physicians often have little to offer these patients. Because different subsets of COPD benefit from different therapies, the management of all COPD patients by a single practice guideline can lead to harmful clinical results. ${ }^{[4]}$ Recent studies indicate that currently used guidelines include expensive medications that do not usually provide patient benefits. ${ }^{[5]}$ 
The ICC has also concluded that the remarkable advances that have been made in understanding genetic contributions to complex diseases could greatly improve the understanding of the subtypes of COPD and their proper care. The causes of COPD as well as appropriate treatments for each subtype need to be determined. What has held scientists back in pursuing this objective for COPD and other complex diseases? Why hasn't the diagnosis and treatment of complex diseases such as COPD improved in the past 40 years? This review assesses the importance of translational research of complex diseases for patient care and health economics. It also analyzes why so little progress has been made in such research, and it reports on recent events in the US that may shed some light on why research on complex diseases has lagged behind.

\section{BURDEN AND COST OF COMPLEX DISEASES}

Since more than 300 million patients worldwide have COPD, it causes a huge patient burden and a major health care cost. Globally it is the third highest cause of death. Neurodevelopmental complex diseases are also major health care problems worldwide. The impact of mental illnesses such as schizophrenia, bipolar disorder, autism spectrum disorder (ASD), and major depression is greater than that of cardiovascular disease or cancer. All these diseases are present in all countries, and they clearly have strong genetic linkages. ${ }^{[6]}$

In terms of disability adjusted life years (DALYs), mental health disorders in developed countries account for the highest number of the total: $17.4 \% .{ }^{[6]}$ Like COPD, accurate diagnosis and specific treatment of severe mental illnesses are lacking. The US National Institute of Mental Health has ruled that the American Psychiatric Association's DSM handbook, which provides the accepted classification of mental illness, is irrelevant for funding or scientific decisions because "Unlike our definitions of ischemic heart disease, lymphoma, or AIDS, the DSM diagnoses are based on a consensus about clusters of clinical symptoms, not any objective laboratory measure. ${ }^{[0]}$,

Because of its genetic links, serious mental illness is a scourge worldwide. More than $75 \%$ of persons with serious mental illness in less developed countries do not receive any treatment for it. It is doubtful that clinicians with specialized training will be available to help cope with this global problem. The best option seems to be primary care physicians directing the efforts to community health workers. The medical model for treating serious mental illness is far from ideal. To begin with, the treatments for these diseases are not effective and they cause serious side effects. Furthermore, the treatments that are used in developed countries have never been shown to be of value in the rest of the world. ${ }^{[6]}$

The problem with dealing with these massive DALYs of suffering is that the cause of the serious mental illnesses is unknown, and the treatments that are used are expensive, ineffective, and dangerous. Scientific discovery is the answer to this dilemma. This should be the highest priority for global health care. The success of this approach in dealing with the scourge of AIDS through the development of scientific understanding of the disease is very instructive and relevant to complex diseases. ${ }^{[6]}$

Many neurologic diseases are also complex and affect large segments of the world's population. There are many independent causes that result in the same outcomes. Such neurologic diseases have neurodevelopmental roots and involve genetic lesions that also occur in severe mental disorders. When one considers the DALYs caused by mental illnesses, neurologic diseases, and respiratory diseases, they account for $25.5 \%$ of all global DALYs. ${ }^{[6]}$ Most of this health burden results from the complex diseases in these categories. This is why translational research that uses the new genomic understanding of complex diseases is so important.

\section{NEW UNDERSTANDING OF GENOMIC LESIONS IN COMPLEX DISEASES}

We now know that the human genome functions as a machine within our living cells to create new genes and new creatures that respond to their environment. It creates new bodily structures and functions as creatures require them to survive.

The image of cell division as simply the copying of a fixed catalog of structural genes is hopelessly outdated. Every time a cell divides, many large- and small-scale rearrangements occur in the cell's DNA. One person's DNA, if stretched out linearly, would extend 400 times the distance of the earth to the moon. It is unimaginable that any mechanism could perfectly and repeatedly replicate such a large sequence even with the many DNA repair enzymes functioning or that such endless repetition would always be desirable.

Genomic mutations and rearrangements drive human evolution and phenotypic diversity as well as cause human disease, so it is highly likely that this source of disease will always be with us. The human genome is not a garden of similar structural genes, it is a wild jungle of DNA sequences mutating, crossing over, and traveling around the genome with unpredictable results. The genome is 
in turmoil, casting the dice during cell division to select the final sequences. The resulting genome that survives in the existing environment is the winner. Genes are in contact with like genes throughout the genome through their similar sequences and affinities for certain protein structures. Huge sequences can be duplicated and inserted near other major duplications when they are summoned or they may be deleted or inverted. It is no surprise that individuals are each so different and also that so many human genetic abnormalities exist.

The impact of changes in genome structure is illustrated by their role in human genetic disease. The effect of copy number variants (CNVs; gene duplications, deletions, and inversions) is larger than single nucleotide variations in genome evolution. CNVs have been implicated in a number of neurodevelopmental disorders such as ASDs. ${ }^{[7]}$ Segmental duplications, often involving long stretches of DNA and multiple genes, are important sources of genomic instability. These hotspots contribute to de novo mutations of DNA, which are important for both human disease and evolution. Studying genome-wide mutation rates and patterns is important for understanding mutation origins, locating hotspots for such events, estimating disease risk, and interpreting novel disease-associated mutations. Studies have convincingly shown that large and dramatic genome changes introduced by large structural mutations can be associated with a multitude of pathological conditions. ${ }^{[8]}$ Sequencing the exome of genes in patients with complex diseases such as autism and comparing them with exomes of control family members reveals numerous mutations among patients. Many of these mutated patient genes are found to belong in networks of related genes, to be in physical contact with each other, and to be coexpressed. Such genes have been found to be involved in the causation of ASD. ${ }^{[9]}$ This approach to diagnosis of complex diseases goes to the source of diagnostic information: the patient's DNA. While this approach will only be applicable to some complex diseases, it should be beneficial for many patients in need.

The following are some of the key biologic discoveries that translational research can use to revolutionize the diagnosis and treatment of complex diseases:

1) The realization that thousands of regulatory RNA molecules do not code for protein synthesis but are transcribed from the human genome. These RNAs are responsible for the human phenotype and for the development of the enormous plasticity of human brain function. They allow humans to think, remember, and create. ${ }^{[10,11]}$

2) Segmental duplications of human DNA have been found to create repurposing areas in which the DNA in a duplicated segment is altered to carry out new functions while allowing the original sequences of DNA to carry on unchanged. This is everyday evolution. Segments with new functions may provide beneficial new capabilities for the individual. In some cases the changes may be damaging and cause disease. Understanding how these hotspots of sequence alteration lead to human disease will be a crucial goal for translational research. ${ }^{[12]}$

3) Half of the human genome is made up of transposonsjumping genes that can move from place to place in the book of our DNA. They can also influence gene expression and fuel evolution. Errors and alteration in this regulation of gene expression can also lead to disease. ${ }^{[13]}$

4) The advances in the techniques of in vitro fertilization and other forms of assisted reproduction open the door to genetic therapy, alteration of cell function, and the control of human development.

5) Gene therapy vectors can be targeted to deliver specific genes to allow production of new, desired gene products in the cells of specific tissues. ${ }^{[14]}$

6) In utero surgical procedures can utilize the regenerative and healing capacity of human embryonic and fetal tissue and can treat diseases and facilitate genetic therapy. ${ }^{[15]}$ 7) Many types of complex diseases are caused by defects in the specific brain genes that are critical to the development of normal brain function. They are neurodevelopmental diseases, and once the causative genes for these diseases are identified it may be possible to mend them using gene therapy or gene editing or improve their function with medications. ${ }^{[2]}$

8) In addition to diseases related to specific gene mutations, gene function can be altered by epigenetic factors that leave their marks on chromatin proteins or cause methylation of the DNA itself, resulting in disease. ${ }^{[3,16,17]}$ COPD may be an example of such diseases.

Physicians who have to depend on patients' non-specific signs and symptoms to diagnose their diseases, will soon be able to access their genotypes to provide accurate diagnosis of their diseases and specific therapy at the DNA level. Translational research that focuses on using these discoveries to diagnose and treat patients will transform the practice of medicine.

\section{SUPPRESSION OF HUMAN MEDICAL RESEARCH DISCOVERIES}

Although major clinical advances could result from such translational research, a simple fact suggests that there are forces operating within society that would prevent such human research from occurring. The discoveries listed above were made many decades ago and little has been done with them. 
These discoveries have been suppressed, concealed, and hobbled by government, business, and religious leaders because they require research to be done on human cells and particularly on human embryonic and fetal tissue.

The tragedy is that the remarkable biologic discoveries could have benefited human society had they not been politically suppressed. This concealment occurred both because these new ideas contradicted existing scientific dogma and because of religious and other reactionary opposition to any alteration of human DNA.

It was and is currently forbidden or illegal throughout the world to make genetic changes in the human germ line DNA. Today, the role of research on human embryos is being debated in medical and scientific communications as well as in public media. ${ }^{[18-20]}$

In utero surgery was pioneered in the 1970s in the US, but because of religious and other conservative objection about allowing the procedure, funding and research was terminated by government health and medical authorities. Almost 40 years later only a few rare conditions are now allowed to be treated by in utero surgery. It would not be approved for research on human embryos or fetuses in the US. In utero surgery has been shown to be a powerful and useful procedure. ${ }^{[15]}$ Embryos and fetuses have remarkable regenerative properties, and even major procedures have been performed with good outcomes. The banning of such valuable surgery because of religious and political objections has impaired progress in worldwide public health.

A future therapy for developmental diseases could involve the use of regulatory molecules that control the proper transcription and translation of human genes. Studies in 2010 found that as much as $90 \%$ of the human genome is transcribed to produce these non-coding regulatory RNA molecules. ${ }^{[21]}$ However, these human regulatory RNA molecules were actually discovered using human fetal and adult brain tissue in 1971. ${ }^{[10]}$ The fact that these molecules were responsible for the plasticity of human brain function and that epigenetic effects influenced human brain gene transcription also resulted from this work. ${ }^{[1,16]}$ These important findings were concealed and ignored for 40 years. The use of human fetal tissue in research was banned, and the research was terminated. Religious and other conservative objections caused this suppression of scientific discoveries.

Embryonic and fetal research will be needed to investigate the genomic lesions that lead to developmental diseases and to test and perfect molecular editing tools that would repair such molecular lesions. Since most individual patients have different gene pathology, extensive research will have to be conducted to identify the individual genetic lesions and to develop therapy. This may be the only way to treat these diseases before their pathological effects on development proceed to completion.

\section{WHY EMBRYO AND FETAL RESEARCH IS NEEDED}

Although individuals' DNA can be easily sampled and sequenced using peripheral blood samples and even fetal DNA can be sequenced from access to maternal blood, there are many experiments that will be needed to test genetic diagnosis and therapy that will require embryonic and fetal tissue. Human fetal tissue is currently used in making vaccines and for other scientific research, but in a very limited way. If complex diseases are to be diagnosed and treated, there will be no substitute for human embryonic and fetal tissue in the research.

Developmental diseases, as the name implies, occur during development. To identify the genes that cause these diseases there must be access to embryos and fetuses to identify the genes that are mutated and to locate CNVs and other genomic lesions that may be present in embryonic and fetal life that cause the diseases. And since the diseases have their origins in early intrauterine life, if there is ever to be a direct therapy to prevent or ameliorate the developmental disease then not only does the research need to be done early in intrauterine life, but treatment would have to be developed and undertaken through in utero surgery early in life.

This use of human tissue should only occur under the following conditions. Scientists should act transparently concerning their work. Women's rights must be respected, and there must be permission for tissue collection and use. Scientists must ensure that potential harm to others does not occur from their work and that the uses of the tissue must be for the benefit of humanity. Scientists should share the results of their work, and the work should conform to global medical and scientific standards.

\section{IMPACT OF ANTI-ABORTION ACTIVISTS ON HUMAN BIOMEDICAL RESEARCH IN THE US}

In the US, religious activists who oppose abortions and birth control use violence, intimidation, political influence, and false, libelous information to attack individuals and organizations that provide patients with abortion or reproductive care. They attempt to prevent patients from seeking these reproductive services. They attack physicians and other health care professionals who work with groups 
that provide reproductive services and support women's right to reproductive freedom.

Planned Parenthood is the largest US organization providing reproductive services, with 700 facilities throughout the US. It receives donations, fees for service, and US government payments. Recently an anti-abortion group financed the production of secretly recorded videos that had been altered and edited to suggest illegal activities by Planned Parenthood affiliates. ${ }^{[18-20]}$ The video producer had masqueraded as a legitimate scientific researcher at the Planned Parenthood facilities in order to request human fetal tissue for research purposes. He used hidden cameras to record conversations with Planned Parenthood representatives. His videos implied that the Planned Parenthood facilities were profiteering by selling fetal tissue from abortuses.

The publicity from the anti-abortion group claiming that Planned Parenthood was "profiteering from selling human body parts" caused national concern and confusion in the US. Conservative representatives in the US House of Representatives initiated legislation to cut all government funding to Planned Parenthood. Planned Parenthood has received about 500 million dollars yearly in government funding for providing services for patients with insufficient finances. Religious and other conservative groups also demanded that Congress ban all use of human tissue for research use.

As more details of the anti-abortion videos became available through coverage on National Public Radio (NPR) and in major news media ${ }^{[20]}$, there were reports that the tapes that had been used to produce the videos had been selectively edited to misrepresent and conceal Planned Parenthood's actual practices and their position on the issue of making fetal tissue available. Planned Parenthood stated that the caveats and details that their representatives had presented during the taping had not been included in the videos, and they criticized other aspects of the video release ${ }^{[21]}$. Analysis of transcripts of the videos provided widely to the media by the producer did not reflect what the individuals in the video had actually said. Journalistic coverage revealed that the inference in the video that the Planned Parenthood group sold fetal tissue was false. They did provide tissue for legitimate researchers, but the only payment required was for expenses in preparing the tissue for the scientists. They made no profit. The videos' information that many Planned Parenthood facilities provided fetal tissue was false. Only a few of the 700 facilities had done so. The inference in the video was that providing fetal tissue was illegal, and this was also false. Providing human fetal tissue for research purposes is legal in the US but not selling it as a profit-making activity.
In spite of the fact that the anti-abortion videos had been falsified, representatives in the US House of Representatives continued to push forward legislation in Congress against Planned Parenthood and fetal research. The Majority Leader of the US Senate, Sen. Mitch McConnell, further demanded that all funding of Planned Parenthood be terminated or else he would refuse to allow a continuing resolution for the US government budget to be passed, and the entire US government would have to shut down. Although this dire result did not as yet occur, the controversy shows the violent opposition of religious and conservative groups to the use of human tissue for research and their willingness to distribute false information and bring harm to the citizens of the US and secondarily to the entire world's economy. A conservative Republican candidate for the US Presidency, Dr. Ben Carson, has said that he would fight for laws that would ban fetal tissue research and that he would fight against abortion even in cases in which the pregnancy resulted from rape or incest.

Although the US government by law must maintain a separation of church and state, it appears that religious dogma, superstition, and prejudice actually control the US government. Unfortunately, since US government funding is what allows US physicians and scientists to do the translational research that serves patients and the public health, the government's opposition to human tissue research will continue to thwart translational research in the future as it has during the past 40 years.

\section{CONCLUSIONS ABOUT THE FUTURE OF HUMAN GENETIC RESEARCH}

Prof. Junjiu Huang and his colleagues in Guangzhou, China, used human embryos to test the ability of the CRISPR-Cas9 editing system to repair a $\beta$-thalassemia gene in the embryos. Important data concerning the abilities and shortcomings of the system were identified in these experiments. This is a good example of human tissue research that supplies useful information but which would very likely be banned in the US. None of the experimental embryos were allowed to develop following the experiment. However, a furor arose in the US over Prof. Huang's experimentation with performing DNA editing in human fetal tissue. ${ }^{[23]}$

US governmental organizations have already held a meeting to develop regulations to impose on medical researchers with regard to research on human embryonic and fetal tissue. During the initial controversy over recombinant DNA experiments in 1975, the Asilomar Conference clarified approaches that researchers could take that would not constitute any biologic danger. However, the Asilomar Conference was organized by Paul Berg, a DNA 
researcher, and not by governmental bodies with political agendas. The Asilomar conference put forward voluntary recommendations whereas a government-convened conference such as the one currently being considered could promulgate regulations with the force of law.

US government political leaders' policy decisions are greatly influenced by the rich US oligarchs who provide the enormous funds to the candidates' Super Pacs that are necessary for candidates to win election. These oligarchs want to maintain the status quo, and they support conservative, religious government policies toward science and research that benefit their financial interests. The politicians support their wishes.

The politicians appoint and control the managers of the US medical research establishment. In the rules that could be made concerning the use of human fetal and embryonic tissue for research, the US governmental agency leaders will follow the politicians' orders about what the policies will be. They are political appointees. As a result, attempts to undertake genetic discovery or genetic therapy using human embryos or fetuses will very likely be banned. The scientists who participate in any discussion on the regulations will have to agree with what their government managers decide about scientific research policy because if they disagree, their funding will be terminated and they will lose their jobs. Since almost all the US scientists affected by research regulations are dependent on government funding for their research and their livelihoods, they would be forced to tailor their research to religious and political requirements and provide results that accommodate religious dogma.

Patient and citizens' advocacy groups need to express their views on the importance of medical research for patients' health and welfare. The ICC strongly endorses the use of human tissue in medical research of respiratory and other complex diseases. It believes this will greatly assist physicians and scientists in discovering the causes and effective treatments for COPD and other deadly diseases.

\section{PHYSICIANS AND SCIENTISTS CANNOT AGREE TO US SUPPRESSION OF SCIENCE}

It appears likely that the US government will act as it has for many decades in suppressing religiously and politically controversial new research. Unfortunately, as in other cases, this could impede the new era of genome science by another generation. If the door to diagnosis and treatment of developmental, epigenetic, and other genomic lesions is closed, the global suffering as a result of complex diseases will continue to increase.
Chinese scientists are moving forward with valuable studies that will facilitate the management of complex diseases while US scientists will be handcuffed, and patients worldwide will suffer. Physicians and scientists outside the US should follow the Chinese scientists' example and work to benefit patients with these severe diseases. Researchers should observe the caveats listed above, and they should be transparent about their work, sensitive to patient concerns and freedom, and careful about potential harm. But they should be bold in discovering the causes and cures of disabling complex diseases to help suffering patients without being impeded by religious dogma.

\section{Conflicts of Interest}

None declared.

\section{REFERENCES}

1. Grouse L. COPD diagnosis: genome first. J Thorac Dis 2015; doi:10.3978/j. ssn.2072-1439.2015.10.38, in press.

2. Coe B, Girirajan S, Eichler E. The Genetic Variability and Commonality of Neurodevelopmental Disease. Am J Med Genet C Semin Med Genet 2012; (2): 118-29.

3. Grouse L. Can epigenetic changes cause COPD? Canaries in the coal mines. J Thorac Dis 2013; 5: 80-1.

4. Rennard S, Locantore N, Delafont B, Tal-Singer R, Silverman EK, Vestbo $\mathrm{J}$, et al. Identification of five COPD subgroups with different prognoses in the ECLIPSE cohort using cluster analysis. Ann Am Thorac Soc 2015; 2: 303-12.

5. Grouse L. Selective polypharmacy for chronic obstructive pulmonary disease. J Thorac Dis 2015; 7: E16-8.

6. The age of unreason. The Economist. July 11, 2015, p4.

7. Duyzend M Eichler E. Genotype-first analysis of the 16p11.2 deletion defines a new type of autism. Biol Psychiatry 2015; 77:769-71.

8. Kloosterman WP, Francioli LC, Hormozdiari F, Marschall T, Hehir-Kwa JY, Abdellaoui A, et al. Characteristics of de novo structural changes in the human genome. Genome Res 2015; 25: 792-801.

9. Hormozdiari F, Penn O, Borenstein E, Eichler EE. The discovery of integrated gene networks for autism and related disorders. Genome Res 2015; 25:142-54.

10. Grouse L, Omenn GA, McCarthy BJ. Studies by DNA-RNA Hybridization of Transcriptional Diversity in Human Brain. J Neurochem 1973; 20:1063-73.

11. Grouse L, Schrier B, Letendre C, Nelson P. RNA Sequence Complexity in Central Nervous System Development and Plasticity. Current Topics in Developmental Biology. Monroy A, Moscona A, Eds., New York: Academic Press 1980: Vol. 16, pp 381-399.

12. O'Roak B, Stessman HA, Boyle EA, Witherspoon KT, Martin B, Lee C, et al. Recurrent de novo mutations implicate novel genes underlying simplex autism risk. Nat Commun 2014; November 24. DOI: 10.1038/ ncomms 6595, 2013.

13. Muotri AR, Chu VT, Marchetto MC, Deng W, Moran JV, Gage FH. Somatic mosaicism in neuronal precursor cells mediated by L1 retrotransposition. Nature 2005; 435: 903-10.

14. Ransom B, Chamberlain J. Gene therapy for muscular dystrophy. Available from: http://healthcarevlogs.com/videos/series/musculardystrophy/. Accessed on November 2, 2015.

15. Barclay WR, McCormick RA, Sidbury JB, Michejda M, Hodgen G. The ethics of in utero surgery. JAMA 1981; 246: 1551-2, 1554-5.

16. Grouse L, Schrier B, Bennett E, Rosenzweig M, Nelson P. Sequence Di- 
versity Studies of Rat Brain RNA: Effects of Environmental Complexity on Rat Brain RNA Diversity. J Neurochem 1978; 30: 191-203.

17. Muotri AR, Zhao C, Marchetto MC, Gage FH. Environmental influence on L1 retrotransposons in the adult hippocampus. Hippocampus 2009; 19: 1002-7.

18. Charo R. Fetal tissue fallout. N Engl J Med 2015; 373: 890-1.

19. Topulos GP, Greene MF, Drazen JM. Planned parenthood at risk. N Engl J Med 2015; 373:10: 963.

20. New York Times coverage of Planned Parenthood videos. Available from: http://www.nytimes.com/2015/08/04/us/politics/planned-parenthood-leader-defends-group-as-senate-blocks-bill-to-end-Its-funding. html?_r=0. Accessed on November 2, 2015.
21. Mercer TR, Gerhardt DJ, Dinger ME, Crawford J, Trapnell C, Jeddeloh JA, et al. Targeted RNA sequencing reveals the deep complexity of the human transcriptome. Nat Biotechnol 2011; 30: 99-104.

22. National Public Radio coverage of Planned Parenthood videos. Available from: http://www.npr.org/2015/08/27/435273173/planned-parenthoodsays-experts-found-misleading-edits-in-videos. Accessed on November $2,2015$.

23. Cyranoski D, Reardon S. Chinese scientists genetically modify human embryos. Nature 2015; April 22. Doi:10.1038/nature.2015.17378.

How to cite this article: Grouse L. Translational genetic research of complex diseases. J TransI Intern Med 2015; 3: 137-143. 